\title{
Muséologies
}

Les cahiers d'études supérieures

\section{Le musée... un autre palimpseste ?}

\section{Alessandra Mariani}

Volume 2, numéro 2, avril 2008

URI : https://id.erudit.org/iderudit/1033585ar

DOI : https://doi.org/10.7202/1033585ar

Aller au sommaire du numéro

Éditeur(s)

Association Québécoise de Promotion des Recherches Étudiantes en Muséologie (AQPREM)

ISSN

1718-5181 (imprimé)

1929-7815 (numérique)

Découvrir la revue

Citer ce document

Mariani, A. (2008). Le musée... un autre palimpseste ? Muséologies, 2(2), 8-11.

https://doi.org/10.7202/1033585ar d'utilisation que vous pouvez consulter en ligne.

https://apropos.erudit.org/fr/usagers/politique-dutilisation/ 


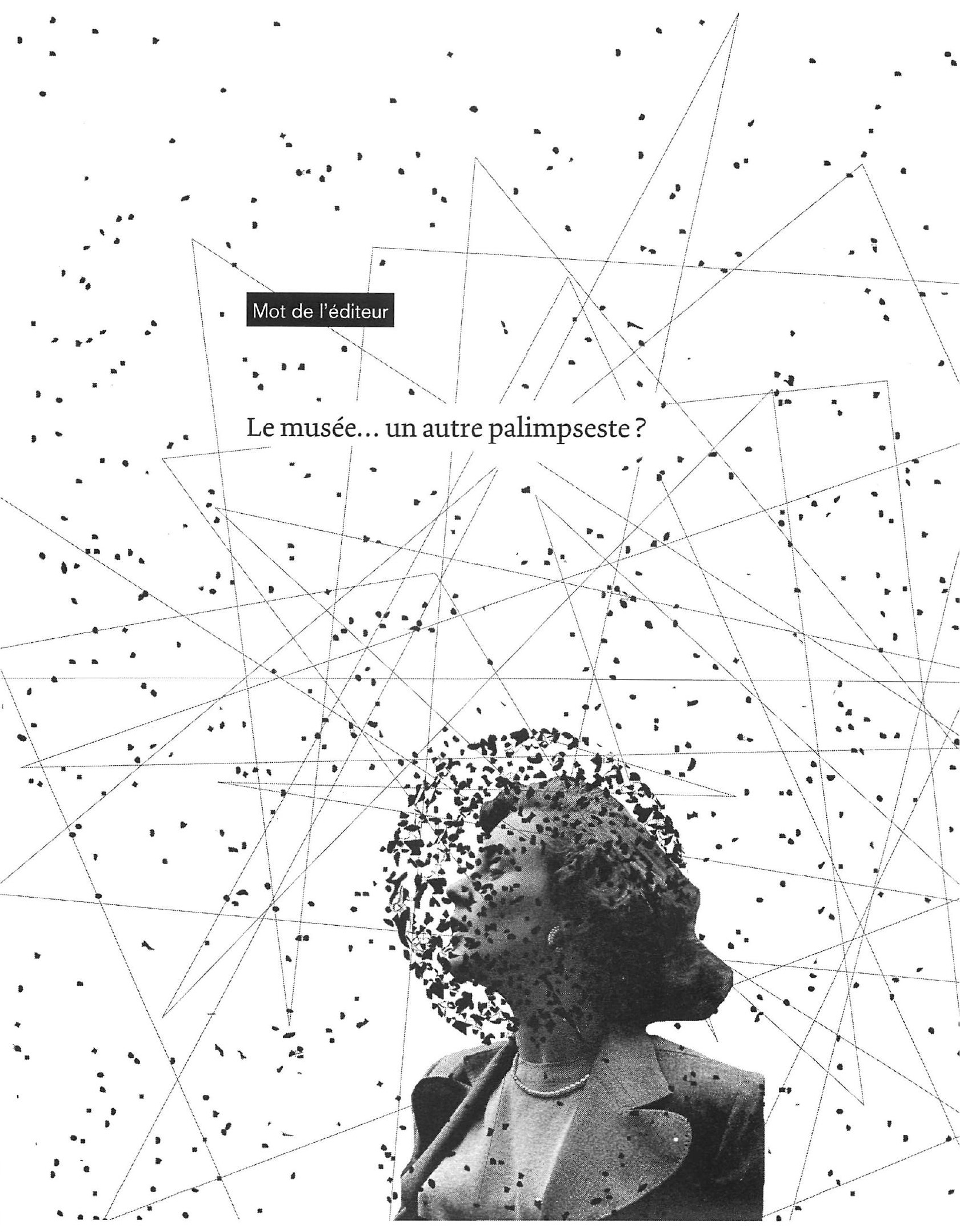




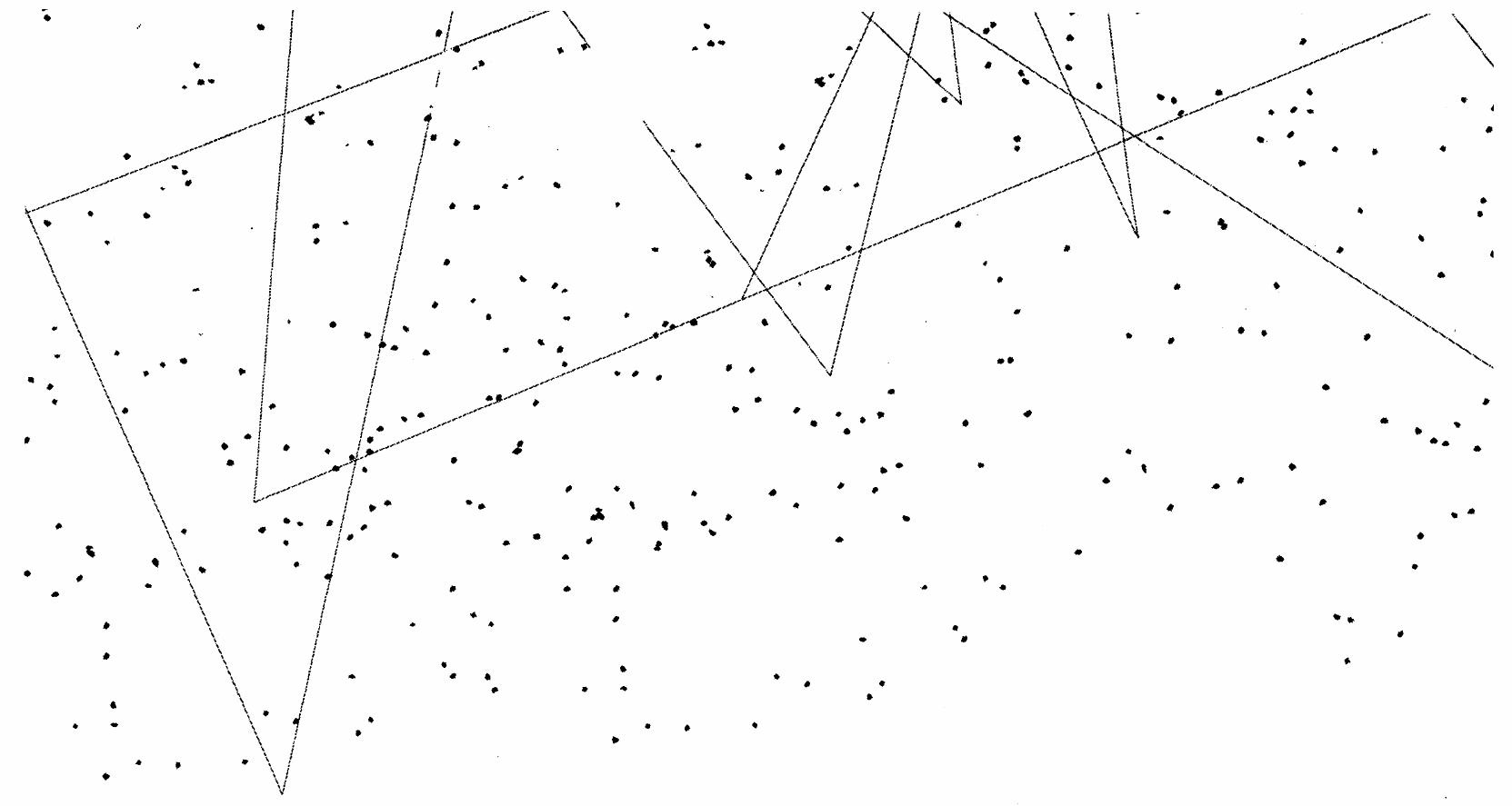

question semblent crier gare à l'avènement des nouvelles formes que prend "cette culture" mais finissent quand même par célébrer sa transformation. Bernard Deloche parle de la «mutation du monde contemporain [...] qui tend à délaisser les cadres institutionnels pour un apparent désordre de la vie sociale qui se construit en marge des codes imposés" "2]. Michel Maffesoli, renchérit et pousse plus loin cette idée : « cette déroute des savoirs en faveur de la prolifération de la Toile [...]. Par-delà ses excès, ce renversement nous invite à retrouver le rythme de la vie au plus profond de nos vies ${ }^{\text {[3]. }}$. Si cette nouvelle culture vivante engendrée par tous les nouveaux moyens de communication semble

[2]

DELOCHE, Bernard La nouvelle culture. La mutation des pratiques sociales ordinaires et l'avenir des institutions culturelles, L'Harmattan, 2007, p. 204. menacer le musée, il n'en demeure pas moins qu'à plusieurs niveaux, il s'est fabriqué une réplique que le temps seul pourra valider : celle d'observatoire interactif de ces mouvances sociales ${ }^{[4]}$. Au bout du compte, nous aussi pourrions envisager que le musée puisse devenir un lieu de sédimentation et de stratification de vécus culturels qui semble avoir déjà conquis ce palimpseste ${ }^{\text {st }}$ de la mémoire qu'on appelle patrimoine...

Dans ce numéro, les articles choisis apportent, chacun à leur manière, une réflexion sur des aspects spécifiques de cette entité en mouvance qu'est le musée actuel. John Impert, se concentre sur les aléas juridiques impliquant héritiers 


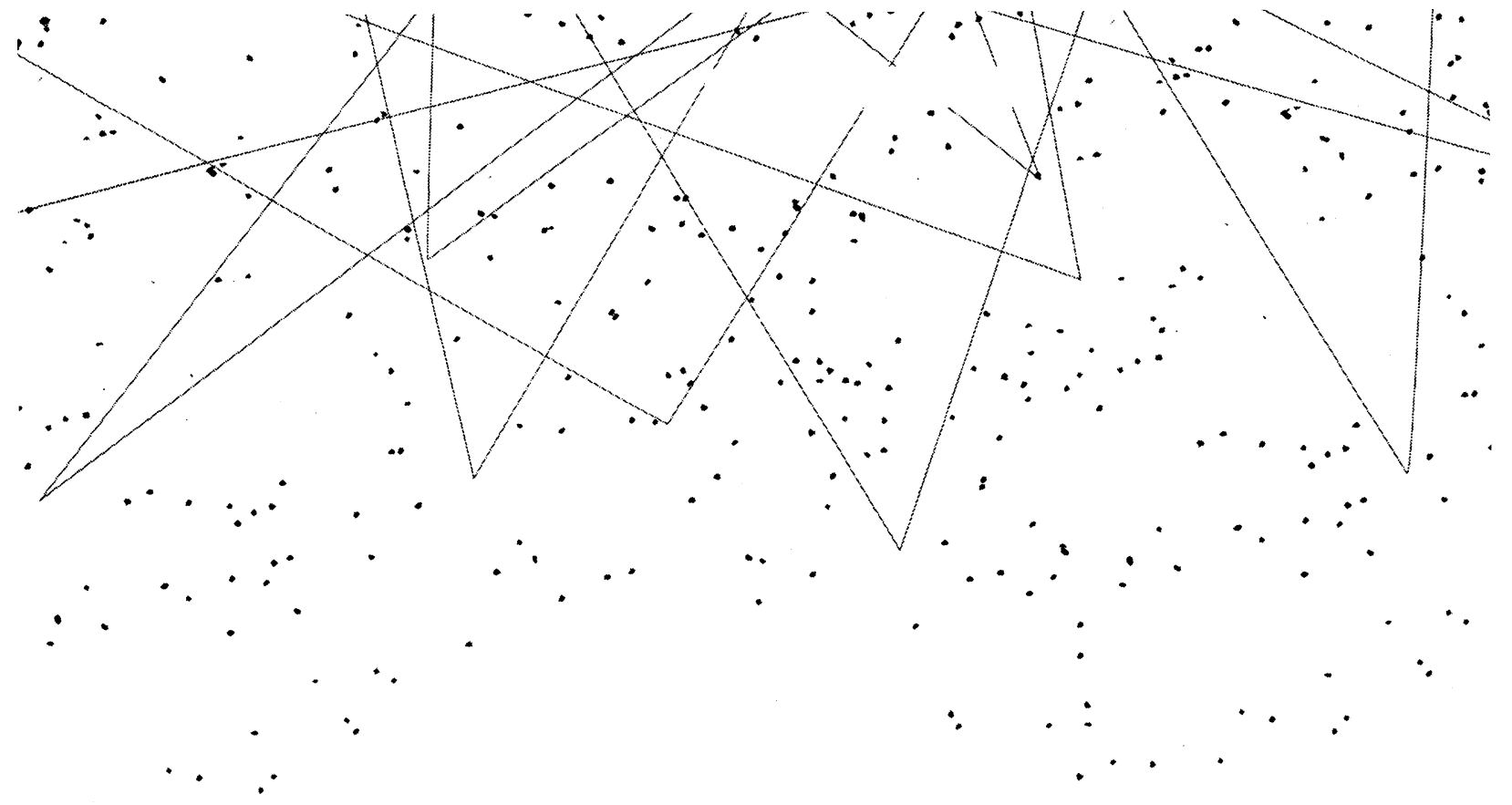

et musées dans des cas de restitutions d'œuvres spoliées en Autriche et sur la façon dont ces cas sont perçus. Geneviève Provencher-St-Cyr se penche sur un système d'actions coopératives qui place l'interaction communautaire au centre du développement muséal régional et qui valide l'approche de la nouvelle muséologie. Marie-Hélène Foisy choisit d'accorder une attention particulière au rôle et à l'importance des publications d'expositions, ces outils de référence, témoins d'une certaine historiographie liée autant à l'acte d'exposer qu'à l'institution qui les commande; et finalement, Laurie Guillemette analyse la place et le rôle de l'écrit dans le format de l'exposition actuelle, du cartel au message qui maintenant s'impose en tant que fil conducteur. Dans la section Carnet, un groupe de jeunes chercheurs du programme conjoint de muséologie UdeM- UQÀM a réfléchi, le temps d'un colloque, sur le rôle social du musée et nous présente un compte-rendu de l'évènement. Ce compte-rendu est ensuite suivi d'une impression à chaud sur le même sujet par Mathieu Dormaels.
Pour conclure, deux directeurs de musée ont accepté de nous offrir leur vision, leurs enseignements et leur interprétation de ces transformations culturelles en cours et comment elles se répercutent au sein de leur musée. Monsieur John Porter, directeur du Musée national des beauxarts de Québec, célèbrera de façon officielle le $400^{\mathrm{e}}$ anniversaire de sa ville : une exposition toute particulière est liée à cet événement, Le Louvre à Québec. Monsieur Marc Mayer, directeur du Musée d'art contemporain de Montréal nous a généreusement fait part des nombreuses innovations qu'il projette. C'est avec un grand enthousiasme que nous avons recueilli leurs propos et que nous avons pu constater que malgré tous les acquis détenus par leurs institutions respectives, leurs attentions sont résolument tournées sur les projets d'avenir. 